\title{
COVID-19: Boons in Disguise
}

\author{
Ishan Agarwal $^{1}$, Dr. Swaroopa Chakole ${ }^{2}$ \\ ${ }^{1}$ Intern, Dept. of Community Medicine, Jawaharlal Nehru Medical College, Datta Meghe Institute of Medical \\ Sciences (Deemed to be University), Sawangi (Meghe), Wardha-442001, Maharashtra, India, \\ ${ }^{2}$ Professor, Dept. of Community Medicine, Jawaharlal Nehru Medical College, Datta Meghe Institute of \\ Medical Sciences (Deemed to be University), Sawangi (Meghe), Wardha-442001, Maharashtra, India, \\ Emails: Ishan82@yahoo.com² drswaroopachakole@gmail.com \\ Type of Article: Review \\ Conflict of Interest: None \\ Funding: DMIMS \\ Ethical Approval: IEC, DMIMS, Wardha.
}

\section{ABSTRACT \\ BACKGROUND}

The COVID-19 pandemic is seriously threatening the humanity by proving its deadliest nature. The new mutated strain needs to studyearlier so that proper measures can be taken as early as possible.

SUMMARY

The COVID-19 is not all attached to thenegative impacts but some unintentional positive impactswas brought by COVID-19. The COVID-19 induced lockdown has proven to be improving air, water, environment quality with giving more space to ecosystem to let thrive the biodiversity. Road accidents and behavioral changes are also another positives and needs to be studied more.

\section{CONCLUSION}

These impacts are surely heartwarming but the real challenge lies in maintain these positives. More study can prove to be effectively strategizing about the further course of the subject.

KEYWORDS: COVID-19, POSITIVE IMPACT, AIR QUALITY, ROAD ACCIDENTS, ENVIRONMENT, BIODIVERSITY.

\section{INTRODUCTION}

The most talked about disease of the century, COVID-19, have proven to be disastrous disease and one of the worse events in the history of the humanity. From initial namelessness and knowing it as respiratory disorder of unknown source it has gained name of coronavirus disease 2019. As it was first identified in Wuhan city of Hubei province in china.(1) The changing epicenter have also created various challenges where symptoms can be vary and may not be universal. Till date as of December 24, 2020, it has infected $78,781,797$ crossing a seventy million mark across around 200 countries and killed 1,731,989 peoples due to its attached medical complications(2). Its impact was so profound, it was declared pandemic in the second week of March after being declared as public health emergency of international concern highlighting its deadly nature. United states of America, India, Brazil, Russian federation, France and united kingdom dominates the top ten list of countries with most number of infection almost accounting more than half of total infected case all over the world(3). The new viral strain also known as severe acute respiratory syndrome novel coronavirus (SARS-COV-2) has also known to be gone through mutation in various parts of Europe particularly united kingdom(4). Necessary measures like banning flights and isolating the incoming passengers are being undertaken measures to avoid any further deterioration of the situation already brought about by the older strain of the coronavirus. It was seeming that all the news connected to COVID-19 was bad and distressful, then some trends were found to be heartwarming and stress relieving as they had a very good impact on the ecosystem as a whole. Improvement in air quality due to reduction in air 
pollution was observed and people experienced a lot cleaner air which they were missing under the race of industrialization(5). Clearer sky which lots of people never experienced in their entire lifetime around their habitat were seen and mountain ranges were visible only to enhance the mood. Water bodies already under severe pressure of polluted water which is coming from the gutter got some breathing space as industries were forced to close down as containment measures were announced. Poaching and tree felling activities which are illegal unless otherwise stated were reduced due to imposition of the movement restrictions. On the other hand, road traffic accidents saw reduction due to less vehicular traffic on roads. Behavioral changes which are vital in healthy lifestyle occurred during pandemic and are very helpful in containing the viral spread. In this article we are going to take a holistic overview of the above factors and discuss about the unseen boons in COVID-19 pandemic.

\section{COVID-19 AND ENVIRONMENT AS A WHOLE}

The case fatalities and humongous infection rate has created the perception of negativity for all the aspects and feeling of nothing can be positive in the current pandemic scenario. But there are certain hidden aspects associated with COVID-19 itself that may create a sense of positivity and goodwill among us in these times of pandemic induced social distress(6). As the pandemic emerged in Chinese city of Wuhan, no one knew that it would be the disease of the century wreaking havoc all over the world. As the devastating effects started emerging out of china and other epicenter of the disease, various governmental agencies and health care authorities had to take steps to ensure people are safe from the infection. In process of containing the viral spread, measures like nationwide lockdown and movement restrictions were imposed and people were told to stay at their residence and do not leave the same unless part of the containment plan. Therefore, by a sudden stroke, majority if the seven billion inhabitants were made to stay at home. Although this was a part of break the chain strategy, several unintentional yet soothing impact were seen and gave the humanity a thought to think upon. Factors like air pollution, water pollution, noise pollution and so many other were on rise and humans were ignorant about such factors. For example air pollution already took a large death toll due to respiratory illness and was due to the developmental activities and transportation needs for the same(7). But due to lockdown huge chunk of the population were sitting at home meaning no vehicles were on road which were creating lethal air pollution. Drastic change was observed in air pollution levels and several factors of air pollutants such as particulate matter 2.5 , particulate matter 10, nitrogen dioxide, Carbon dioxide, Sulphur dioxide, smog etc. were found to be reduced heavily as they are particularly emitted from vehicles which were absent from the roads due to imposed lockdown. Major polluted metro cities such as Mumbai, New Delhi and other cities were already reeling under huge burden of air pollution got some breather in literal sense(8). In New Delhi, capital city of India and a major industrial hub and center for almost all major activities in world's second largest economy, people experienced first time cleaner air and could see blue sky which they never had seen their entire life since industrialization. Some cities near Himalayan ranges in Punjab which never saw the Himalayas started to see its peak from so far away due to cleaner air around their surroundings. According to the world air quality report 201914 of the 20 most polluted cities with air pollution are from India. Ghaziabad, a satellite town of the Capital city of New Delhi, which already was reeling under the immense pressure of air pollution topped the ranking if worlds most polluted cities. But due to lockdown imposed, a massive 
reduction of around 85 percent in particulate matter 2.5 (PM 2.5) pollutant was seen attributed to lowered number of vehicles on the street and closing down of industries. This reduction was compared to three months prior levels of pollutants when all was running normally. Also, particulate matter 10, nitrogen dioxide, Sulphur dioxide saw reduction in concentration as compared to three months before. PM 10 pollutant saw a whopping 50.8 percent reduction, nitrogen dioxide saw 48.7 percent reduction which is quite impressive and Sulphur dioxide which is mainly emitted from industries saw 14.3 percent reduction all values compared to three months prior levels(9). PM 2.5 and PM 10 can cause severe lung disease and disorder, also they get attached to the alveolar sacs and makes it difficult to diffuse oxygen and other gases properly. Satellite images also showed some relieving pictures with clearer scene. Aerosol optical depth (AOD) was improved considerably for the betterment of the environment. In India under national clean air program, a yardstick of air quality measurement was set up known as air quality index which monitors real time air pollutants and convert it into index 700 being the maximum and worse figure. It also saw a drop in air pollution and the indicators were turning green(10).

Along with air pollution another factor which is harmful to human being is water pollution. It also saw reduction in pollutant levels as industries were closed and sewage treatment plant were having less material to treat. Industrial effluents are the major cause of water body pollution which are also used for drinking water purpose. A major indicator through which one can measure the levels of the pollution is biological oxygen demand (BOD) indicator(6). More is the demand of oxygen in marine biology, more is the water polluted in that ecosystem. It also saw a reduction with BOD standing at less than 3 parts per million at various stretches of the river Ganges, a main river and harbors many lives directly as well as indirectly. A pollution control authority of India namely central pollution control board (CPCB) has found increased marine activity and water was found to be suitable for propagation of healthy marine ecosystem(11). Also, as religious activities were restricted and reduced remarkably, the ritualistic waste, cremation saw reduction thus improving the water quality of the Ganges. In case of Yamuna, another major lifeline on the Indian subcontinent, thetoxic foam which forms over the surface of the river due to detergent and industrial untreated chemicals were absent at several stretches of the river where it was seen prominently(7).

Biodiversity was also affected in positive way as the human interference was halted for some time. Animals were found to be roaming on the streets like they are here for reclaiming what once was theirs. The delicate balance between environment and development was disturbed for a while. It was somewhat restored(12). Due to lockdown and movement restrictions, poaching activities of exotic species and endangered animals also saw reduction giving them some breather. Temperature also moderated itself as external harmful influence was reduced for a while. Noise pollution which is quite neglected and often underplayed and which can have harmful consequences like anxiety, sleeplessness and so on, also saw reduction as no major industrial and vehicular activities were happening. Beaches were self-clean due to no tourist littering there and harming the ecosystem as a whole. Less illegal cutting of trees was observed and jungles were safe for some time giving their original ambience back. It was a time to heal from the injuries and brunt that human activities gave to the nature(13).

\section{COVID-19 AND ROAD ACCIDENTS}

As the vehicles were absent from the roads and streets except the essential services providers, the negative aspects attached to it such as accidents, injuries and deaths 
due to accidents were reduced drastically. A statistical analysis between the lockdown restrictions showed that in Californian state of United States of America after the pandemic of COVID-19 started there was almost 50 percent in accidents and accidental casualties due to vehicular reasons. Although there is a need of official cohort study about the lockdown and lowering in accidents numbers.Also,financial and economic condition also affects the commuting patterns of the population. When the income level goes down, people tends to reduce the commuting distance and rather take public transport and walk on foot(14). Studies found out that as pandemic started and many people lost their livelihood or got no wages, it can also be linked to reduced number of commuters on road and hence a smaller number of accidents therefore resulting into lowering of accidental casualties. Also driving under influence of toxic substances can be found in less numbers as during lockdown these substances were hard to find due to movement restrictions. High risk and vulnerable section of population such as elderlies which are considered as risky drivers due to their deteriorating motor and neural control also were confined to their respective homes as lockdowns was in force. Therefore, this section of risky drivers was out of bound of roads lowering the chances of supposed collisions. Also working from home culture, if continued after the pandemic is fully over then it will have lasting impact on the commuting pattern of people(15). Less pollution and less noise will be experienced by people around the world. The major cities experience heavy traffic load each day polluting every aspect they can and inducing lots of stress, anxiety due to lots of noise of honking and smoke from the vehicles. If the work from home is successfully adopted then majority of the car owning section of the society will travel less means win win situation for all as he or she will avoid stress and environment will have less pollutants in it(16).

\section{BEHAVIORAL CHANGES IN COVID- 19}

COVID-19 has brought several drastic changes in human lifestyle and changed the way we live. The devastating effects which are brought by the coronavirus made us to think upon our interaction with other elements in the ecosystem. As the virus is not yet defenestrated from the society, it is important to know which changes are necessary in order successfully tackle the pandemic. Several changes were automatically ingrained in our day to day working which are good not only for the pandemic survival but for long term also.Wearingmasks, maintaining physical distancing, exercise, mediation and yoga, sanitizing hands at regular intervals, having healthy meals are some of the habits that people picked up during pandemic. These habits have immense benefits when seeing through comprehensively. Wearing masks not only just ward off the coronavirus infection but also other communicable disease like Tuberculosis, Asthma and other bronchial diseases. So, by wearing masks the goal of eliminating may also serve and lowering in number of communicable diseases may be seen. Proper mask as according to guidelines will help in achieving all the related goals. Physical distancing may be difficult to maintain but in the long run it has various other positive effects and will also serve as a good habit. A lot of contagious diseases like dysentery, diarrhea, loose motion, and bowel disorder happens due to lack of hygienic habits and environment(17). Sanitizing merely can serve the purpose of safeguarding from not only coronavirus but also from other preventable contagious diseases. This along with proper diet with necessary antioxidants and probiotics and exercise with mediation and yoga will make the person free from all the ailments and rest coronavirus will also be taken care of. 
Pandemic has brought families together and work from home has given a lot of time and space to improve the relations with our loved ones. The strained relationships due to lack of time and other avoidable factors induces anxiety and sometimes depression. Therefore, it is necessary to give it a shot to improve such relations and lockdown has proven no better opportunity. Various activities can be undertaken in order to improve emotional quotient which is in most of cases is underdeveloped and necessary to develop to ensure the overall wellbeing of the person. It helps us to handle emotional crisis and gives us strength in the times when everything is not alright. As the pandemic induced lockdown starts, various shops were forced to close including liquor and other consumable sin goods shops. So, people found compelling reasons to quit their respective addictions and start a new journey with life. Consumption of $\sin$ goods only proves to be bad, financially, economically as well as physically and emotionally too. Various bad consequences are attached to it and even leads to various emotional and medical complications which can become unmanageable in future course of time if not addressed in time. Also, philanthropy and humane acts were seen as many were left foodless and starving. Various people along with different non-governmental organization started to provide foods, clothing and shelter to the needy ones in the times of distress. Students left stranded in another city and had no money were provided with food and money to survive the pandemic(18). This act of kindness was very heart warming. Stray dogs are dependent on the foods that is left over on street and roads. But due to containment measures like movement restrictions and lockdown people were unable to give foods to them and the stray dogs, cats and rodents were left hungry. Several animal lover organization step forward to provide food to these city creatures and help them to get rid of their hunger. On international level the plight of poorer nations was highlighted again and lots of help in financial and other forms poured out to them which only showed the act of kind ness much needed in such distressful times. Countries like India, which is considered as hub for medicines were providing hydroxychloroquine and other personal protective equipment's not only to poorer nations but also to developed countries which lacked the capacity to make them(19). Crumbling health infrastructure again highlighted the need of increased expenditure in health sector and boost up the facilities that are inadequate for any such scenario that world is facing now (20-24). A number of interesting reviews on positive effects of Covid-19 were reported (25-28).

\section{CONCLUSION}

If the hypotheses of the animal sourced transmission of the coronavirus disease 2019 , it is very bad that our interaction with the environment is not sustainable. The environment must be taken into account before doing any developmental activity that may potentially disturb the balance of the nature. We are what we eat therefore we should be cautious about having exotic and endangered species on our plate as some species of animals must letunconsumed. The positive changes were indirectly brought about by the pandemic of COVID-19 must be cherished and maintained because this time the nature has warned us as we disturbed the balance. Already polluted environment needs extra attention to restore to its original form. Before designing any policy, governing authorities needs to take into account the environmental factor and do the environmental impact assessment to analyze the damage that will cause the activity. Coexisting with nature sustainably is the only way to ensure that not ours but future generations to get the bearable earth and they can also live here peacefully. Behavioral habits that good in nature may be sustained and can prove not 
only in current pandemic scenario where it is of utmost importance but in future scenario too where such situation may arise as according to World Health Organization (WHO) has already said that COVID-19 may not be the last pandemic that the humanity will face. Reduced accidents are the result of artificial activity and may resume again but creating awareness about safe practices on road and making people to take public transport can have lasting impact on various aspects at once whether be it air pollution or economical status. Finally, the earth is not here to be exploited. The nature rebound whenever the balance is disturbed. As the famous saying goes, the earth is not our ancestral property but it is borrowed from our future generations so we have to take care to not ruin to the extent that it becomes inhabitable after certain years.

\section{REFERENCES}

1. Dushyant Bawiskar, Pratik Phansopkar, Ayurva Vilas Gotmare. COVID-19 Facets: Pandemics, Curse and Humanity. Int J Res Pharm Sci. 2020 Aug 6;11(SPL1):385-90.

2. COVID-19 Map [Internet]. Johns Hopkins Coronavirus Resource Center. [cited 2020 Dec 24]. Available from: https://coronavirus.jhu.edu/map.html

3. WHO Coronavirus Disease (COVID19) Dashboard [Internet]. [cited 2020 Dec 24]. Available from: https://covid19. who.int

4. Wise J. Covid-19: New coronavirus variant is identified in UK. BMJ [Internet]. 2020 Dec 16 [cited 2020 Dec 23];371:m4857. Available from: https://www.bmj.com/content/371/b mj.m4857

5. Togun T, Kampmann B, Stoker NG, Lipman M. Anticipating the impact of the COVID-19 pandemic on TB patients and TB control programmes. Ann Clin Microbiol Antimicrob [Internet]. 2020 May 23 [cited 2020 Nov 9];19. Available from: https://www.ncbi.nlm.nih.gov/pmc/ar ticles/PMC7245173/

6. Verma A, Prakash S. IMPACT OF COVID-19 ON ENVIRONMENT AND SOCIETY. 2020 Jul 2;

7. Aman MA, Salman MS, Yunus AP. COVID-19 and its impact on environment: Improved pollution levels during the lockdown period A case from Ahmedabad, India. Remote Sens Appl Soc Environ [Internet]. 2020 Nov 1 [cited 2020 Oct 26];20:100382. Available from: http://www.sciencedirect.com/science /article/pii/S2352938520302743

8. Li L, Li Q, Huang L, Wang Q, Zhu $\mathrm{A}, \mathrm{Xu} \mathrm{J}$, et al. Air quality changes during the COVID-19 lockdown over the Yangtze River Delta Region: An insight into the impact of human activity pattern changes on air pollution variation. Sci Total Environ [Internet]. 2020 Aug 25 [cited 2020 Oct 26];732:139282. Available from: http://www.sciencedirect.com/science /article/pii/S0048969720327996

9. Chauhan A, Singh RP. Decline in PM2.5 concentrations over major cities around the world associated with COVID-19. Environ Res [Internet]. 2020 Aug 1 [cited 2020 Oct 26];187:109634. Available from: http://www.sciencedirect.com/science /article/pii/S0013935120305272

10. Kumar P, Hama S, Omidvarborna H, Sharma A, Sahani J, Abhijith KV, et al. Temporary reduction in fine particulate matter due to 'anthropogenic emissions switch-off' during COVID-19 lockdown in Indian cities. Sustain Cities Soc [Internet]. 2020 Nov 1 [cited 2020 Oct 26];62:102382. Available from: http://www.sciencedirect.com/science /article/pii/S221067072030603X

11. Wu D, Lu J, Liu Y, Zhang Z, Luo L. Positive effects of COVID-19 control measures on influenza prevention. Int J Infect Dis. 2020 Apr 1;95. 
12. Lokhandwala S, Gautam P. Indirect impact of COVID-19 on environment: A brief study in Indian context. Environ Res [Internet]. 2020 Sep 1 [cited 2020 Oct 26];188:109807. Available from: http://www.sciencedirect.com/science /article/pii/S0013935120307027

13. Sarmadi M, Marufi N, Kazemi Moghaddam V. Association of COVID-19 global distribution and environmental and demographic factors: An updated three-month study. Environ Res [Internet]. 2020 Sep 1 [cited 2020 Oct 26];188:109748. Available from: http://www.sciencedirect.com/science /article/pii/S0013935120306411

14. Peden M, World Health Organization. World report on road traffic injury prevention: information kit. Geneva, Switzerland: World Health Organization; 2004.

15. Oguzoglu U. COVID-19 Lockdowns and Decline in Traffic Related Deaths and Injuries. 2020;19.

16. Saladié Ò, Bustamante E, Gutiérrez A. COVID-19 lockdown and reduction of traffic accidents in Tarragona province, Spain. Transp Res Interdiscip Perspect [Internet]. 2020 Nov 1 [cited 2020 Nov 9];8:100218. Available from: http://www.sciencedirect.com/science /article/pii/S2590198220301299

17. Long VJ, Liu JC. BEHAVIORAL CHANGES DURING THE COVID19 PANDEMIC: RESULTS OF A NATIONAL SURVEY IN SINGAPORE. medRxiv [Internet]. 2020 Aug 7 [cited 2020 Dec 23];2020.08.06.20169870. Available from:

https://www.medrxiv.org/content/10. 1101/2020.08.06.20169870v1

18. Lotfinejad N, Peters A, Pittet D. Hand hygiene and the novel coronavirus pandemic: the role of healthcare workers. J Hosp Infect [Internet]. 2020 Aug [cited 2020 Nov
9];105(4):776-7. Available from: https://www.ncbi.nlm.nih.gov/pmc/ar ticles/PMC7270549/

19. India supplies medicines to African Countries [Internet]. [cited 2020 Dec 24]. Available from: https://mea.gov.in/pressreleases.htm?dtl/32675/India_supplie s_medicines_to_African_Countries.

20. Anjankar Ashish, P., P. Anjankar Vaibhav, J. Anjankar Anil, and K. Lata. "Positive Aspects of Covid 19 Pandemic: A Blessing in Disguise." International Journal of Research in Pharmaceutical Sciences 11, no. Special Issue 1 (2020): 187-91. https://doi.org/10.26452/ijrps.v11iSPL 1.2371.

21. Borage, S., and P. Shelotkar. "Positive Effects of Covid-19 on Earth." International Journal of Research in Pharmaceutical Sciences 11, no. Special Issue 1 (2020): 234-38. https://doi.org/10.26452/ijrps.v11iSPL 1.2704 .

22. Kamdi, P.S., and M.S. Deogade. "The Hidden Positive Effects of Covid-19 Pandemic." International Journal of Research in Pharmaceutical Sciences 11, no. Special Issue 1 (2020): 276-79. https://doi.org/10.26452/ijrps.v11iSPL 1.2712 .

23. Srivastava, R., N. Rathi, N. Thosar, S. Baliga, M. Khubchandani, V. Mohite, J. Mehta, and R. Waykar. "Contemporary Treatment Modalities for the Management of SARS-CoV-2 Positive Patients: An Overview." International Journal of Research in Pharmaceutical Sciences 11, no. Special Issue 1 (2020): 839-46. https://doi.org/10.26452/ijrps.v11iSPL 1.3090 .

24. Sonone, A., A. Hande, M. Gawande, and S. Patil. "Sickle Cell Individuals Are Less Vulnerable for Corona Virus Disease 2019-an Enigma." International Journal of Research in Pharmaceutical Sciences 11, no. Special Issue 1 (2020): 1015-17. 
https://doi.org/10.26452/ijrps.v11iSPL 1.3427.

25. Sonone, A., A. Hande, M. Gawande, and S. Patil. "The Mystery of Low COVID-19 Mortality Rate in India." International Journal of Research in Pharmaceutical Sciences 11, no. Special Issue 1 (2020): 1180-82. https://doi.org/10.26452/ijrps.v11iSPL 1.3586 .

26. Chawla, D., P. Wagh, S. Ali, U. Jadhav, and B. Ghewade. "Impact of COVID 19 Pandemic on Tuerculosis." International Journal of Research in Pharmaceutical Sciences 11, no. Special Issue 1 (2020): 1084-88. https://doi.org/10.26452/ijrps.v11iSPL 1.3533 .

27. Gaidhane, S., N. Khatib, Q.S. Zahiruddin, A. Gaidhane, S. Telrandhe, and P. Godhiwal. "Depression, Anxiety and Stress among the General Population in the Time of COVID-19 Lockdown: A Cross-Sectional Study Protocol." International Journal of Research in Pharmaceutical Sciences 11, no. Special Issue 1 (2020): 360-64. https://doi.org/10.26452/ijrps.v11iSPL 1.2726 .

28. Gaidhani, K.V., and S.P. Chalakh. "COVID-19 Is a Janapadodwans Vyadhi in Ayurveda-a Review." International Journal of Research in Pharmaceutical Sciences 11, no. Special Issue 1 (2020): 1363-66. https://doi.org/10.26452/ijrps.v11iSPL 1.3642 . 